\title{
Relation between maternal thrombophilia and stillbirth according to causes/ associated conditions of death
}

\author{
F. Monari a , S. Alberico b, L. Avagliano ${ }^{\text {c }}$, I. Cetin ${ }^{\text {d }}$, S. Cozzolino ${ }^{\text {e }}$, G. Gargano ${ }^{\text {a }}$, L. Marozio ${ }^{\text {f }}$, F. Mecacci ${ }^{\text {g, }}$, \\ I. Neri ${ }^{\text {a }}$, A.L. Tranquilli h ${ }^{\text {, P. Venturini }}{ }^{\text {a }}$, F. Facchinetti ${ }^{\text {a, } *, 1}$ \\ a University of Modena and Reggio Emilia, Mother-Infant Dept, Modena, Italy \\ b IRCCS Burlo Garofalo, Ob \& Gyn Dept, Trieste, Italy \\ c School in Prenatal development, Diagnosis and fetal therapy, University of Milano, Italy \\ ' University of Milano, DISG Luigi Sacco, Milano, Italy \\ e University of Milano-Bicocca, Ob \& Gyn Unit, Monza, Italy \\ ${ }^{\mathrm{f}}$ University of Turin, Dept Obstet Gynaecol, Torino, Italy \\ ${ }^{g}$ University of Florence, $\mathrm{Ob}$ \& Gyn Dept, Firenze, Italy \\ ${ }^{\mathrm{h}}$ Marche Polytechnic University, Maternal and Child Sciences, Ancona, Italy
}

\section{A R T I C L E I N F O}

\section{Article history:}

Received 28 December 2010

Received in revised form 19 August 2011

Accepted 23 August 2011

\section{Keywords:}

Factor V Leiden

Factor II mutation

Acquired thrombophilia

Stillbirth

Placenta vascular disorders

\begin{abstract}
A B S T R A C T
Objective: To investigate maternal thrombophilia in cases of Stillbirth (SB), also an uncertain topic because most case series were not characterised for cause/associated conditions of death.

Study design: In a consecutive, prospective, multicentre design, maternal DNA was obtained in 171 cases of antenatal SB and 326 controls (uneventful pregnancy at term, 1:2 ratio). Diagnostic work-up of SB included obstetric history, neonatologist inspection, placenta histology, autopsy, microbiology/chromosome evaluations. Results audited in each centre were classified by two of us by using CoDAC. Cases were subdivided into explained SB where a cause of death was identified and although no defined cause was detected in the remnants, 64 cases found conditions associated with placenta-vascular disorders (including preeclampsia, growth restriction and placenta abruption - PVD). In the remnant 79 cases, no cause of death or associated condition was found.

Antithrombin activity, Factor V Leiden, G20210A Prothrombin mutation (FII mutation) and acquired thrombophilia were analysed.

Results: Overall, the presence of a thrombophilic defect was significantly more prevalent in mothers with SBs compared to controls. In particular, SB mothers showed an increased risk of carrying Factor II mutation $(\mathrm{OR}=3.2,95 \% \mathrm{Cl}: 1.3-8.3, \mathrm{p}=0.01)$, namely in unexplained cases. Such mutation was significantly associated also with previous SB (OR $=8.9,95 \% \mathrm{CI} 1.2-70.5)$. At multiple logistic regression, Factor II mutation was the only significantly associated variable with SB (adj OR=3.8, 95\% CI: 1.3-13.5).

Conclusion: These data suggest that Factor II mutation is the only condition specifically associated with unexplained SB and could represents a risk of recurrence. PVD-associated condition is unrelated to thrombophilia.
\end{abstract}

(c) 2011 Elsevier Ireland Ltd. All rights reserved.

\section{Introduction}

Thrombophilia (i.e., congenital mutation of coagulation factors $\mathrm{V}$ and II, reduction of anticoagulatory protein or the presence of lupus anticoagulant/phospholipid antibodies) has been proposed to be related to adverse pregnancy outcomes. Considering that inherited thrombophilia is a predisposition to a hypercoagulation state with formation of thrombi, researchers have focussed their attention on

* Corresponding author at: Unit of Obstetrics, Azienda Ospedaliero Universitaria, Via del Pozzo 71, 41100 Modena, Italy. Tel.: +39 0594222512.

E-mail address: Facchi@unimore.it (F. Facchinetti).

${ }^{1}$ For the Italian Stillbirth Study Group. pregnancy complications related to circulatory disorders. Studies performed in women having preeclampsia (PE), foetal growth restriction (FGR), placenta abruption and foetal demise gave conflicting data, mainly because of differences in population features and clinical definitions [1-3]. However, the combination of adverse obstetric outcomes with the presence of antiphospholipid antibodies has been recognised as a separate syndrome, termed antiphospholipid syndrome, and it represents the most common acquired thrombophilia [4].

The issue of foetal demise or stillbirth (SB) is further complicated by poor knowledge and low interest in the subject, which has been addressed only in recent years [5]. The main problem in comparing available data has been the absence of a uniform definition amongst different countries [6]. 
Although a multiplicity of risk factors for SB has been described in several studies [7-9], a definite cause of foetal death in utero could be ascertained in less than one third of the cases, thus complicating communication with parents and management of the next pregnancy [10]. Accordingly, it has not been determined whether thrombophilia should be considered a risk factor for SB $[11,12]$.

In a comprehensive view, SB should be interpreted as an interaction of foetal conditions, maternal environment and circumstances. Maternal thrombophilia could be one of many negative maternal predisposing factors. Unfortunately, in the clinical series published thus far, the described confounding factors have seldom been taken into account.

Therefore, this case-control study evaluated the association between thrombophilia and SB according to maternal and foetal conditions known to be involved in foetal death.

\section{Materials and methods}

\subsection{Subjects}

This population-based study was part of a comprehensive national programme to investigate the epidemiology, risk factors, causes and management of SB and was sponsored by the Italian Ministry of Education, University and Research. Recruitment occurred from June 2005 to June 2007 in the maternal-foetal medicine units of 9 university hospitals in northern and central Italy. The Ethics Committee approved the study, including collection and storage of blood for extracting DNA. Sensitive information was treated according to the Italian "Privacy Act".

Cases were categorised as stillborn when neonates at $\geq 22$ weeks of gestation or $>500 \mathrm{~g}$ (if gestational ultrasound age was not available) had Apgar scores of 0 for the 1 st and 5 th minutes and were not actively resuscitated. Consecutive antepartum SB cases were included, and intrapartum cases were excluded. Ninety-one percent of the pregnancies were dated by a first trimester ultrasound; the foetal weight criterion was utilised in only 2 cases.

Controls, defined as women having an uneventful pregnancy at term, were randomly enrolled amongst women delivering at the same hospitals. The women were recruited in a 2:1 ratio for each case and matched for age ( \pm 2 years) and ethnicity.

Socio-demographic variables, maternal and obstetric history, pregnancy course, circumstances of SB and parturition were already on file. Data were collected through an ad hoc electronic form.

To classify the causes of death, the same work-up protocol was adopted by participant centres, which included careful obstetric history and circumstances of SB diagnosis collected in an ad hoc form attached to maternal diary, placenta histology, stillborn autopsy, microbiology evaluation (cultures of neonatal blood and placenta swab; superficial swabs from neonate), chromosome analysis (from either amniotic fluid or blood, or fascia lata) and neonate inspection. As expected, cytogenetic cultures failed in $40 \%$ of cases; autopsy and placenta histology was available in $>95 \%$ of subjects. Causes of death and/or significant associated circumstances were recorded and audited at each participating centre. Then, the data were reviewed by an obstetrician (FF) and neonatologist (GG), which used up-to-date CoDAC classification [13]. Discrepancies were discussed and solved by consensus.

Thus, SBs have been subdivided into three groups. Cases where a cause of death was recognised (excluding those with placenta involvement) were grouped as EXPLAINED, (Table 1). Clinical disorders belonging to abnormal vascular/placenta function were grouped as PVD and include small for gestational age newborns (birthweight $<10$ th percentile according to gestational age and sex), preeclampsia and severe hypertension according to the American College of Obstetricians and Gynecologists [14], and placenta abruption. Finally, cases without a defined cause of death were grouped as UNEXPLAINED.
Table 1

Classification of stillborn according to CoDAC.

\begin{tabular}{|c|c|c|c|c|c|c|}
\hline \multirow{2}{*}{\multicolumn{3}{|c|}{ Explained Cases }} & \multicolumn{4}{|c|}{ Unexplained Cases $(\mathrm{COD}=851)$} \\
\hline & & & \multicolumn{3}{|c|}{$\begin{array}{l}\text { Placenta vascular disorders } \\
\text { (PVD) }\end{array}$} & \multirow{2}{*}{$\begin{array}{l}\text { Totally } \\
\text { Unexplained } \\
\mathrm{n}\end{array}$} \\
\hline Cause of death & Code & $\mathrm{n}$ & Associated condition & Code & $\mathrm{n}$ & \\
\hline Malformations & 300 & 7 & & & & \\
\hline Genetic disorders & & & Small for & 810 & 26 & \\
\hline •Trisomies & 370 & 4 & gestational age & & & \\
\hline •Aneuploidies & 380 & 3 & & & & \\
\hline Infections & & & Preeclampsia & 714 & 21 & \\
\hline •Bacteria & 070 & 3 & & & & \\
\hline •SGB & 050 & 3 & & & & \\
\hline •Viral & 090 & 4 & & & & \\
\hline Immune hydrops & 470 & 4 & $\begin{array}{l}\text { Abruption of the } \\
\text { placenta }\end{array}$ & 630 & 13 & \\
\hline $\begin{array}{l}\text { Twin-to-twin } \\
\text { transfusion } \\
\text { syndrome }\end{array}$ & 671 & 1 & $\begin{array}{l}\text { Severe gestational } \\
\text { hypertension }\end{array}$ & 712 & 4 & \\
\hline Total number & & 29 & & & 63 & 79 \\
\hline
\end{tabular}

\subsection{Methods}

Antithrombin activity (AT) was routinely evaluated in all patients at admission. Eight to 12 weeks after delivery, blood was drawn from the women for DNA analysis to look at factor V Leiden and factor II G20210A mutations and assess anticardiolipin antibodies and lupus anticoagulants. The assessment for acquired thrombophilia was repeated 6-12 weeks later. The molecular diagnosis of factor $V$ Leiden was performed according to Bertina et al. [15]. The prothrombin gene mutation was detected using a slight modification of the Poort et al. method [16]. The concentrations of IgG/IgM anticardiolipin antibodies were determined by specific ELISA (cut-off values, IgG_21 GPL/mL and IgM $\_21 \mathrm{MPL} / \mathrm{mL}$ ). The presence of lupus anticoagulant was determined as previously described [17]. The presence of anticardiolipin antibodies and/or lupus anticoagulant was grouped as acquired thrombophilia.

Statistical analysis was performed with SPSS 17 software using the Chi-square test, analysis of variance, and logistic regression. To calculate the study power, we used thrombophilia prevalence data reported in Italian women with uneventful pregnancies [18,19]. According to Martinelli et al. [19], we hypothesised a three-fold prevalence in cases with SB. Hence, with a power of $0.80,150$ cases and 300 controls would be sufficient to detect a significant difference $(\mathrm{p}<0.05)$ between groups.

\section{Results}

Out of 239 eligible women, maternal thrombophilia was investigated in 171 consecutive cases. Although thrombophilia was advice amongst exams pertinent to SB evaluation, one centre disagree and some of the remnants started to collect data later.

Cause of death and associated condition are detailed in Table 1.

Cases and controls were homogeneous with respect to age, parity, education, and ethnicity. BMI $>25$ was found significantly more represented in cases respect with controls (Table 2). Additional clinical features of the 3 subgroups of SB are reported in Table 3. Age, BMI and ethnicity were equally distributed amongst groups. Stillbirth at term was significantly more prevalent in the UNEXPLAINED subgroup ( $\mathrm{OR}=5.04,95 \% \mathrm{CI}: 2.24-11.50)$, whereas the presence of a previous SB was reported slightly more in the PVD subgroup.

Overall, the presence of a thrombophilic defect was significantly more prevalent in mothers with SBs compared to mothers with uneventful full-term pregnancies (Table 4). Factor V Leiden frequencies and acquired thrombophilia were similar in cases and controls whilst SB mothers showed an increased risk of carrying Factor II mutation $(\mathrm{OR}=3.2,95 \% \mathrm{Cl}: 1.3-8.3, \mathrm{p}=0.01)$. In both cases and controls, Factor V Leiden and Factor II mutation were heterozygous. No cases of homozygous mutations were detected. 
Table 2

Clinical features of the mothers in cases and controls. Data are reported as $\mathrm{N}$ with \% in brackets.

\begin{tabular}{|c|c|c|}
\hline & Stillborn $\mathrm{n}=171$ & Controls $\mathrm{n}=326$ \\
\hline \multicolumn{3}{|l|}{ Age } \\
\hline$\leq 25$ years & $18 / 171(10.5)$ & 40/287 (13.9) \\
\hline 26-34 years & $89 / 171(52)$ & $151 / 287(52.6)$ \\
\hline$\geq 35$ years & $64 / 171(37.4)$ & $96 / 287(33.4)$ \\
\hline \multicolumn{3}{|l|}{ Ethnicity } \\
\hline Caucasian & $124 / 171(72.5)$ & $233 / 326(71.5)$ \\
\hline Non Caucasian & $47 / 171(27.5)$ & $93 / 326(28.5)$ \\
\hline \multicolumn{3}{|l|}{ Nulliparity } \\
\hline & $80 / 171(46.8)$ & $166 / 315(52.7)$ \\
\hline \multicolumn{3}{|l|}{ Previous stillbirth } \\
\hline & $11 / 170(6.5)$ & $10 / 322(3.1)$ \\
\hline \multicolumn{3}{|l|}{ Education } \\
\hline$\leq 8$ years & $34 / 121(28.1)$ & $60 / 278(21.6)$ \\
\hline$>8$ years & $87 / 121(71.9)$ & $218 / 278(78.4)$ \\
\hline \multicolumn{3}{|c|}{ Pre-pregnancy BMI* } \\
\hline$<20$ & 13/149 (8.7) & 24/295 (8.1) \\
\hline $21-25$ & $77 / 149$ (51.7) & $189 / 295(64.1)$ \\
\hline $26-30$ & $41 / 149$ (27.5) & $64 / 295(21.7)$ \\
\hline$>30.1$ & $18 / 149(12.1)$ & $18 / 295(6.1)$ \\
\hline
\end{tabular}

Table 5 reports the thrombophilia data for the 3 subgroups of SB. Factor II mutation was the only significant variable associated with unexplained SB $(p=0.007)$. As a whole, inherited thrombophilia (Factor II + Factor V Leiden) was represented equally in EXPLAINED (14.3\%), PVD (11.7\%) and UNEXPLAINED (15.2\%) subgroups. The UNEXPLAINED SB subgroup had a risk of $3.2(95 \% \mathrm{CI}: 1.3-7.4 ; \mathrm{p}=0.005)$ for carrying an inherited thrombophilia defect.

AT was normal in every subject, and no AT deficiencies were found.

The presence of thrombophilia has been correlated with several confounding factors, including ethnic group, previous SB, BMI, gestational age at death, preeclampsia, and HELLP Syndrome and FGR. The obstetric history demonstrated that $11 / 88$ pluriparas (12.5\%) had a prior SB. Factor II mutation was significantly associated with a positive history for $\mathrm{SB}(\mathrm{OR}=8.9,95 \% \mathrm{CI}: 1.2-70.5)$. The remnant variables were not significantly correlated with either inherited or acquired thrombophilia.

Table 3

Clinical features of the mothers in 3 subgroups of SB. Data are reported as $\mathrm{N}$ with \% in brackets. Gestational age and the rate of previous stillbirth are significantly different among subgroups.

\begin{tabular}{lccc}
\hline & Explained $n=29$ & PVD $n=63$ & Unexplained $\mathrm{n}=79$ \\
\hline Age & & & \\
$\leq 25$ years & $3(10.3)$ & $9(14.3)$ & $8(10.1)$ \\
$26-34$ years & $12(41.4)$ & $36(57.1)$ & $42(53.1)$ \\
$\geq 35$ years & $14(48.3)$ & $18(28.6)$ & $29(36.8)$ \\
Ethnicity & & & \\
$\quad$ Caucasian & $24(82.7)$ & $50(79.4)$ & $65(82.3)$ \\
$\quad$ Asian & $2(6.9)$ & $7(11.1)$ & $6(7.6)$ \\
Others & $3(10.4)$ & $6(9.5)$ & $8(10.1)$ \\
Nulliparity & & & \\
& $9(31)$ & $31(49.2)$ & $43(54.4)$ \\
Previous abortion $(<20$ weeks) & $8(27.6)$ & $12(19)$ & $10(12.6)$ \\
& & & \\
Previous stillbirth & $1(3.4)$ & $7(11.1)$ & $3(3.8)$ \\
& & & \\
Gestational age & $17(58.6)$ & $38(60.3)$ & $23(29.1)$ \\
$<32$ weeks & $7(24.1)$ & $18(28.6)$ & $22(27.8)$ \\
$32^{+1}-37$ weeks & $5(17.3)$ & $7(11.1)$ & $34(43.1)$ \\
$>37^{+1}$ weeks & & & \\
Pre-pregnancy BMI & $17(58.6)$ & $33(52.4)$ & $42(53.1)$ \\
$<25$ & $10(34.5)$ & $20(31.7)$ & $26(32.9)$ \\
$25.1-30$ & $2(6.9)$ & $10(15.9)$ & $11(14)$ \\
$>30.1$ & & & \\
\hline
\end{tabular}

Table. 4

Prevalence of maternal thrombophilic factors in stillborn and controls. Number of cases with \% reported in brackets.

\begin{tabular}{lcrl}
\hline & \multicolumn{1}{l}{ Stillborn } & \multicolumn{1}{l}{ Controls } & OR \\
\hline FV Leiden & $9 / 167(5.4)$ & $8 / 318(2.5)$ & $2.2(0.8-6.4)$ \\
FII mutation & $14 / 164(8.5)$ & $9 / 319(2.8)$ & $3.2(1.3-8.3)$ \\
Acquired thrombophilia & $10 / 171(5.8)$ & $11 / 326(3.4)$ & $1.8(0.7-4.6)$ \\
Any thrombophilia & $33 / 171(19.2)$ & $28 / 334(8.4)$ & $2.8(1.6-5.0)$ \\
\hline
\end{tabular}

A multiple logistic regression was build-up. Dependent variable was cases with SB. Independent confounding variables included in the model were ethnicity, parity, BMI, previous SB, Factor V Leiden, Factor II mutation and acquired thrombophilia. Factor II mutation was the only significantly associated variable $(F=12.3, p=0.001)$, explaining $3.9 \%$ of the variance. Factor II adjusted $\mathrm{OR}=3.8,95 \% \mathrm{CI}$ : 1.3-13.5.

\section{Discussion}

As a whole, the data demonstrated that mothers presenting with SBs have an increased risk of carrying thrombophilic defects. More specifically, Factor II mutation is the single defect associated with the occurrence of SB. The findings were derived primarily from the figures representing the UNEXPLAINED subgroup.

Despite two meta-analyses [11,12], conclusions have been difficult to draw due to the heterogeneity of clinical samples, study design and confounding factors. The most troubling issue has been the definition of "unexplained SB", which largely depends on the diagnostic workup performed in each one of the primary studies [13]. A strength of this study is that enrolled cases have been thoroughly investigated and audited, allowing classification of causes and conditions associated with death, whereas this was reported only in a minority of previously published studies [19-23]. Recently, one study reported data after categorisation of causes of death, including also paternal thrombophilia [24].

In light of our previous data, whether Factor $\mathrm{V}$ Leiden prevalence in SB is increased with respect to uneventful pregnancies has remained questionable. It seems likely that increasing sample size also Factor V Leiden would reach statistical significance in our cases series. In any case, the reported odd risks have been quite low, ranging 1.5 to 4.5 [19-24].

Table 5

Prevalence of thrombophilia in the 3 subgroups of SB vs controls. Data are reported as $\mathrm{N}$ and \% in brackets. OR is reported with $95 \%$ Confidence interval.

\begin{tabular}{llll}
\hline \multicolumn{3}{l}{ Explained SB versus controls } & \\
\hline & Explained & \multicolumn{1}{l}{ Controls } & OR \\
\hline FV Leiden & $2 / 28(7.1)$ & $8 / 318(2.5)$ & $2.9(0.2-16.4)$ \\
FII mutation & $2 / 28(7.1)$ & $9 / 319(2.5)$ & $2.6(0.2-14.2)$ \\
Acquired thrombophilia & $0 / 29(0)$ & $11 / 326(3.4)$ & $/$
\end{tabular}

SB associated with placenta vascular disorders (PVD) versus controls

\begin{tabular}{llll}
\hline & PVD & \multicolumn{1}{l}{ Controls } & OR \\
\hline FV Leiden & $3 / 60(5.0)$ & $8 / 318(2.5)$ & $2.0(0.2-8.8)$ \\
FII mutation & $4 / 60(6.7)$ & $9 / 319(2.5)$ & $2.5(0.6-9.2)$ \\
Acquired thrombophilia & $3 / 63(4.8)$ & $11 / 326(3.4)$ & $1.4(0.02-5.8)$
\end{tabular}

Totally unexplained SB (Unexplained) versus controls

\begin{tabular}{llll}
\hline & Unexplained & Controls & OR \\
\hline FV Leiden & $4 / 79(5.1)$ & $8 / 318(2.5)$ & $2.1(0.5-7.8)$ \\
FII mutation & $8 / 76(10.5)$ & $9 / 319(2.5)$ & $4.1(1.4-12.0)^{\mathrm{a}}$ \\
Acquired thrombophilia & $7 / 79(8.9)$ & $11 / 326(3.4)$ & $2.8(0.9-8.1)$ \\
Total SB & $172(100)$ & $326(100)$ & - \\
\hline
\end{tabular}

a Significant association. 
According to our data, prothrombin gene mutation appeared to represent a risk factor for SB. A prospective study by Said et al. [25] has confirmed this association despite few cases occurring in the cohort under study; this was expected from the SB prevalence, which ranges $4-7 / 1000$ in developed countries. Interestingly enough, we also found that Factor II mutation is the only thrombophilic defect presenting an association with a positive history of SB, perhaps indicating an increased risk of recurrence.

These conclusions have been challenged by a study performed in low-risk populations, which did not find an association between factor II mutation and pregnancy loss [23]. However, although the sample size and appropriate prospective design measures were sufficient, the study included pregnancy loss as both first trimester abortions and foetal deaths occurring below the 20th week of gestation. Thus, conclusions cannot directly apply to SB occurrence, which is defined as foetal death in utero with at least 20 weeks of gestational development. The same limitation apply to the recent meta-analysis of Rodger et al. [26].

In addition to SB, maternal thrombophilia has been associated with several adverse pregnancy outcomes including severe preeclampsia [18] and placenta abruption [27]; it is still debated whether foetal growth restriction has to be linked to thrombophilia [28]. Also, all of the above conditions were included amongst risk factors for SB thereby complicating the picture [5-10]. Nevertheless, whilst clinical evidence has suggested that placental dysfunction is correlated with in utero demise, no histological [24-29] or functional [30] evidence has supported thrombophilia as the linking pathogenetic mechanism. Indeed, composite placenta-mediated pregnancy complications seem not associated with Factor V Leiden [26]. Prothrombin gene mutation figures however show a trend to be linked to the above described adverse pregnancy outcomes.

A limitation of this study is that we used only term live-birth pregnancy as controls. This would have missed an association between thrombophilias and adverse pregnancy outcomes resulting in preterm live-births. However, in most of the cases, case-control studies were composed by uneventful pregnancies.

In conclusion, when SBs were deeply investigated and classified, the association of foetal demise and maternal thrombophilia appeared doubtful. Although this study suggested that prothrombin gene mutation is a condition specifically associated with unexplained intrauterine death, its impact seems low considering it explain a very small proportion of the variance. However, prothrombin gene mutation seems to represent a risk factor for recurrence [31]. In light of multifactorial approaches and considering the relatively low association strength, we should consider thrombophilia to be one amongst other risk factors participating to SB occurrence.

\section{Conflict of interest statement}

The authors report no conflicts of interest. The authors alone are responsible the content and writing of the paper.

\section{References}

[1] Rodger MA, Paidas M, Mc Lintock C, Middeldorp S, Kahn S, Martinelli I, Hague W, Rosene Montella K, Greer I. Inherited thrombophilia and pregnancy complications revisited. Obstet Gynecol 2008;112:320-4.

[2] Middeldorp SJ. Thrombophilia and pregnancy complications: cause or association? Thromb Haemost 2007;5(Suppl 1):276-85.

[3] Weiner Z, Younis JS, Blumenfeld Z, Shalev E. Assessment of uterine placental circulation in thrombophilic women. Semin Thromb Hemost 2003;29:213-8.

[4] De Groot PG, Derksen HVM. Pathophysiology of the antiphospholipid syndrome. J Thromb Haemost 2005;3:1854-60.
[5] Smith GCS, Fretts RC. Stillbirth. Lancet 2007;370:1715-25.

[6] Facchinetti F, Reddy U, Stray-Pedersen B, Baronciani D, Requejo JH. Stillbirth International Group. International issues in stillbirth. Neonatal Med 2008 Jun;21(6): 425-8.

[7] Goldenberg RL, Kirby R, Culhane JF. Stillbirth: a review. J Mat Fet Neonat Med 2004;16:79-94.

[8] Simpson LL. Maternal medical diseases: risk of antepartum fetal death. Semin Perinatol 2002;26:42-50.

[9] Getaun D, Ananth CV, Kinzler WL. Risk factors for antepartum and intrapartum stillbirth: a population-based study. Am J Obstet Gynaecol 2007;196:499-507.

[10] Fretts RC. Etiology and prevention of stillbirth. Am J Obstet Gynaecol 2005;193: 1923-35.

[11] Rey E, Kahn SR, David M, Shrier I. Thrombophilic disorders and fetal loss: a metaanalysis. Lancet 2003;361:901-8.

[12] Robertson L, Wu O, Langhorne P, Twaddle S, Clark P, Lowe GD, et al. The thrombosis: risk and economic assessment of thrombophilia screening (TREATS) study. Thrombophilia in pregnancy: a systematic review. Br J Haematol 2006;132: 171-96.

[13] Flenady V, Frøen JF, Pinar H, Torabi R, Saastad E, Guyon G, et al. An evaluation of classification systems for stillbirth. BMC Pregnancy Childbirth 2009 Jun 19;9:24.

[14] ACOG Committee on Obstetric Practice. ACOG practice bulletin. Diagnosis and management of preeclampsia and eclampsia. Number 33, January 2002. American College of Obstetricians and Gynecologists. Int J Gynecol Obstet 2002;77:67-75.

[15] Bertina RM, Koeleman BPC, Koster T, Rosendaal FR, Dirven RJ, deRonde H, Van der Velden PA, Reitsma PH. Mutation in blood coagulation factor V associated with resistance to activated protein C. Nature 1994;369:64-7.

[16] Poort SR, Rosendaal FR, Reitsma PH, Bertina RM. A common genetic variation in the 3-untranslated region of the prothrombin gene is associated with elevated plasma prothrombin levels and an increase in venous thrombosis. Blood 1996;88:3698-703.

[17] Wilson WA, Gharavi AE, Koike T, Lockshin MD, Branch DW, Piette JC, et al. International consensus statement on preliminary classification criteria for definite antiphospholipid syndrome: report of an international workshop. Arthritis Rheum 1999;42:1309-11.

[18] Mello G, Parretti E, Marozio L, Pizzi C, Lojacono A, Frusca T, et al. Thrombophilia is significantly associated with severe preeclampsia: results of a large-scale, casecontrolled study. Hypertension 2005;46:1270-4.

[19] Martinelli I, Taioli E, Cetin I, Marinoni A, Gerosa S, Villa MV, et al. Mutations in coagulation factors in women with unexplained late fetal loss. N Engl J Med 2000 Oct 5;343(14):1015-8.

[20] Many A, Elad R, Yaron Y, Eldor A, Lessing JB, Kupferminc MJ. Third-trimester unexplained intrauterine fetal death is associated with inherited thrombophilia. Obstet Gynecol 2002 May;99(5 Pt 1):684-7.

[21] Gris JC, Quéré I, Monpeyroux F, Mercier E, Ripart-Neveu S, Tailland ML, et al. Casecontrol study of the frequency of thrombophilic disorders in couples with late foetal loss and no thrombotic antecedent-the Nîmes Obstetricians and Haematologists Study 5 (NOHA5). Thromb Haemost 1999 Jun;81(6):891-9.

[22] Alonso A, Soto I, Urgellés MF, Corte JR, Rodríguez MJ, Pinto CR. Acquired and inherited thrombophilia in women with unexplained fetal losses. Am J Obstet Gynecol 2002;187:1337-42.

[23] Silver RM, Zhao Y, Spong CY, Sibai B, Wendel Jr G, Wenstrom K, Samuels P, Caritis SN, Sorokin Y, Miodovnik M, O'Sullivan MJ, Conway D, Wapner RJ, Eunice Kennedy Shriver National Institute of Child Health and Human Development Maternal-Fetal Medicine Units (NICHD MFMU) Network. Prothrombin gene G20210A mutation and obstetric complications. Obstet Gynecol 2010;115:14-20.

[24] Korteweg FJ, Erwich JJ, Folkeringa N, Timmer A, Veeger NJ, Ravisé JM, et al. Prevalence of parental thrombophilic defects after fetal death and relation to cause. Obstet Gynecol 2010 Aug;116:355-64.

[25] Said JM, Higgins JR, Moses EK, Walker SP, Borg AJ, Monagle PT, et al. Inherited thrombophilia polymorphisms and pregnancy outcomes in nulliparous women. Obstet Gynecol 2010;115:5-13.

[26] Rodger MA, Betancourt MT, Clark P, Lindqvist PG, Dizon-Townson D, Said J, et al The association of factor $\mathrm{V}$ leiden and prothrombin gene mutation and placentamediated pregnancy complications: a systematic review and meta-analysis of prospective cohort studies. PLoS Med Jun 15 2010;7(6):e1000292 Review.

[27] Facchinetti F, Marozio L, Frusca T, Grandone E, Venturini P, Tiscia GL, et al. Maternal thrombophilia and the risk of recurrence of preeclampsia. Am J Obstet Gynecol 2009;200:46.e1-5.

[28] Infante-Rivard C, Rivard GE, Yotov WV, Génin E, Guiguet M, Weinberg C, et al. Absence of association of thrombophilia polymorphisms with intrauterine growth restriction. N Engl J Med 2002 Jul 4;347(1):19-25.

[29] Ariel I, Anteby E, Hamani Y, Redline RW. Placental pathology in fetal thrombophilia. Hum Pathol 2004;35:729-33.

[30] Salomon O, Seligsohn U, Steinberg DM, Zalel Y, Lerner A, Rosenberg N, et al. The common prothrombotic risk factors in nulliparous women do not compromise blood flow in the feto-maternal circulation and are not associated with preeclampsia or intrauterine growth restriction. Am J Obstet Gynecol 2004;191: 2002-9.

[31] Monari F, Facchinetti F. Management of subsequent pregnancy after antepartum stillbirth. A review. J Matern Fetal Neonatal Med 2010;23:1073-84. 